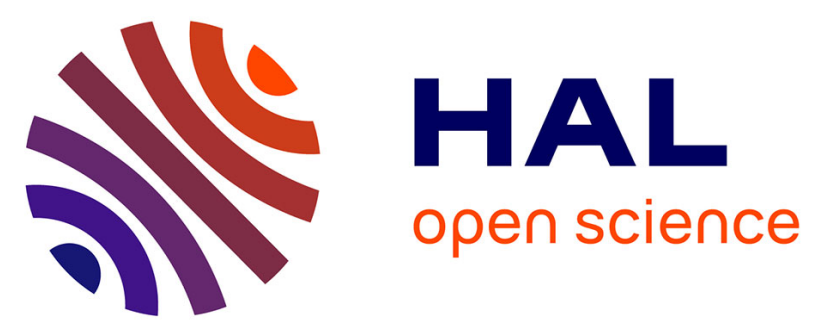

\title{
Ticagrelor versus clopidogrel in elective percutaneous coronary intervention (ALPHEUS): a randomised, open-label, phase $3 \mathrm{~b}$ trial
}

Paul Guedeney, Mohamad El Kasty, Mikael Laredo, Raphaëlle Dumaine, Grégory Ducrocq, Eric Vicaut, Johanne Silvain, Jean-Philippe Collet, Gilles

Montalescot, Mathieu Kerneis, et al.

\section{To cite this version:}

Paul Guedeney, Mohamad El Kasty, Mikael Laredo, Raphaëlle Dumaine, Grégory Ducrocq, et al.. Ticagrelor versus clopidogrel in elective percutaneous coronary intervention (ALPHEUS): a randomised, open-label, phase 3b trial. The Lancet, 2020, 396 (10264), pp.1737-1744. 10.1016/S01406736(20)32236-4 . hal-03038048

\section{HAL Id: hal-03038048 https://hal.science/hal-03038048}

Submitted on 30 Jul 2021

HAL is a multi-disciplinary open access archive for the deposit and dissemination of scientific research documents, whether they are published or not. The documents may come from teaching and research institutions in France or abroad, or from public or private research centers.
L'archive ouverte pluridisciplinaire HAL, est destinée au dépôt et à la diffusion de documents scientifiques de niveau recherche, publiés ou non, émanant des établissements d'enseignement et de recherche français ou étrangers, des laboratoires publics ou privés. 


\title{
Ticagrelor versus clopidogrel in elective percutaneous coronary intervention (ALPHEUS): a randomised, open-label, phase $3 b$ trial
}

\author{
Johanne Silvain, Benoit Lattuca, Farzin Beygui, Grégoire Rangé, Zuzana Motovska, Jean-Guillaume Dillinger, Ziad Boveri, Philippe Brunel, \\ Thibault Lhermusier, Christophe Pouillot, Elisa Larrieu-Ardilouze, Franck Boccara, Jean-Noël Labeque, Paul Guedeney, Mohamad El Kasty, \\ Mikael Laredo, Raphaëlle Dumaine, Grégory Ducrocq, Jean-Philippe Collet, Guillaume Cayla, Katrien Blanchart, Petr Kala, Eric Vicaut, \\ Gilles Montalescot, on behalf of the ALPHEUS investigators*
}

\section{Summary}

Background Percutaneous coronary intervention (PCI)-related myonecrosis is frequent and can affect the long-term prognosis of patients. To our knowledge, ticagrelor has not been evaluated in elective PCI and could reduce periprocedural ischaemic complications compared with clopidogrel, the currently recommended treatment. The aim of the ALPHEUS study was to examine if ticagrelor was superior to clopidogrel in reducing periprocedural myocardial necrosis in stable coronary patients undergoing high-risk elective PCI.

Methods The ALPHEUS study, a phase 3b, randomised, open-label trial, was done at 49 hospitals in France and Czech Republic. Patients with stable coronary artery disease were eligible for the study if they had an indication for PCI and at least one high-risk characteristic. Eligible patients were randomly assigned (1:1) to either ticagrelor (180 mg loading dose, $90 \mathrm{mg}$ twice daily thereafter for 30 days) or clopidogrel (300-600 mg loading dose, 75 mg daily thereafter for 30 days) by use of an interactive web response system, and stratified by centre. The primary outcome was a composite of PCI-related type 4 (a or b) myocardial infarction or major myocardial injury and the primary safety outcome was major bleeding, both of which were evaluated within $48 \mathrm{~h}$ of PCI (or at hospital discharge if earlier). The primary analysis was based on all events that occurred in the intention-to-treat population. The trial was registered with ClinicalTrials.gov, NCT02617290.

Findings Between Jan 9, 2017, and May 28, 2020, 1910 patients were randomly assigned at 49 sites, 956 to the ticagrelor group and 954 to the clopidogrel group. 15 patients were excluded from the ticagrelor group and 12 from the clopidogrel group. At $48 \mathrm{~h}$, the primary outcome was observed in 334 (35\%) of 941 patients in the ticagrelor group and $341(36 \%)$ of 942 patients in the clopidogrel group (odds ratio [OR] 0.97, 95\% CI $0 \cdot 80-1 \cdot 17 ; \mathrm{p}=0 \cdot 75$ ). The primary safety outcome did not differ between the two groups, but minor bleeding events were more frequently observed with ticagrelor than clopidogrel at 30 days (105 [11\%] of 941 patients in the ticagrelor group vs 71 [8\%] of 942 patients in the clopidogrel group; OR 1.54, 95\% CI 1·12-2.11; p=0 0070).

Interpretation Ticagrelor was not superior to clopidogrel in reducing periprocedural myocardial necrosis after elective PCI and did not cause an increase in major bleeding, but did increase the rate of minor bleeding at 30 days. These results support the use of clopidogrel as the standard of care for elective PCI.

Funding ACTION Study Group and AstraZeneca.

\section{Introduction}

Percutaneous coronary intervention (PCI) is widely used in patients with stable coronary artery disease and is considered a safe procedure. Over the past decade, the rates of associated stent thrombosis, Q-wave myocardial infarction, stroke, and death have substantially decreased, and they are now considered rare periprocedural complications. However, development of highly sensitive cardiac troponin assays has led to the documentation of frequent periprocedural myonecrosis. Although often asymptomatic, these periprocedural complications can delay hospital discharge, and have been associated with an increased risk of future major cardiac adverse events, including death. ${ }^{1-4}$ Side branch occlusion, slow coronary flow, and embolisation are potential mechanisms of atherothrombotic complications and could be reduced by more effective antiplatelet therapy than the recommended combination of aspirin and clopidogrel. Intravenous cangrelor has shown benefit over clopidogrel in PCI, reducing ischaemic complications at the expense of increased bleeding. ${ }^{5-7}$ Despite a higher risk of bleeding, prasugrel and ticagrelor, with a more potent and rapid onset of action compared with clopidogrel, are now the standard of care for PCI in patients with acute coronary syndrome, but have not been well investigated in elective PCI. ${ }^{8,9}$ The
Sorbonne Université, ACTION Study Group, INSERM UMRS1166, Hôpital PitiéSalpêtrière (AP-HP), Paris, France (Prof) Silvain MD, P Guedeney MD, M Laredo MD ProfJ-PCollet MD, Prof G Montalescot MD); ACTION Study Group, Cardiology Department, Nîmes University Hospital, Montpellier University, Nîmes, France (B Lattuca MD, Prof G Cayla MD); ACTION Study Group, Département de Cardiologie, CHU de Caen, Caen, France (Prof F Beygui MD, Prof K Blanchart MD); Département de Cardiologie, $\mathrm{CH}$ de Chartres, Chartres, France (G Range MD); Third Faculty of Medicine, Charles University and Cardiocentre Kralovske Vinohrady, Prague, Czech Republic (Prof Z Motovska MD); Université de Paris, Department of Cardiology, Lariboisière Hospital, Assistance Publique-Hôpitaux de Paris, INSERM U942, Paris, France (J-G Dillinger MD); ACTION Study Group, Département de Cardiologie, $\mathrm{CH}$ de Bastia, Bastia, France (Z Boueri MD); Hôpital Privé Dijon Bourgogne-Cardiologie Interventionelle GCIDB VALMY, Dijon, France (P Brunel MD); Département de Cardiologie, $\mathrm{CHU}$ de Toulouse, Toulouse, France (T Lhermusier MD); Département de Cardiologie, Clinique Sainte Clotilde, La Réunion, France (C Pouillot MD); Service de Cardiologie, CHU de Poitiers, 
Poitiers, France (E Larrieu-Ardilouze MD); AP-HP, Hôpitaux de l'Est Parisien, Hôpital Saint-Antoine, Department of Cardiology, Sorbonne Université-INSERM UMR S_938, Centre de Recherche Saint-Antoine, Paris, France (Prof F Boccara MD); GCS de Cardiologie de la Côte Basque, CH Bayonne, Bayonne, France (J-N Labeque MD) Département de Cardiologie, Grand Hôpital de l'Est Francilien site Marne-La-Vallée Marne-la-Vallée, France (M El Kasty MD); Les Grands Prés Cardiac Rehabilitation Centre, Villeneuve St Denis, France (R Dumaine MD); Université de Paris, Hôpital Bichat, AP-HP, French Alliance for Cardiovascular Trials (FACT), INSERM U1148, Paris, France (Prof G Ducrocq MD); University Hospital Brno, Medical Faculty of Masaryk University Brno, Brno, Czech Republic (ProfP Kala MD); ACTION Study Group, Unité de Recherche

Clinique, Hôpital Fernand Widal (AP-HP), Paris, France (Prof EVicaut MD); and Statistique, Analyse et

Modélisation Multidisciplinaire EA 4543, Université Paris Panthéon Sorbonne, Paris, France (Prof E Vicaut)

Correspondence to: Prof Gilles Montalescot, ACTION Study Group, Sorbonne Université, INSERM UMRS1166 Hôpital Pitié-Salpêtrière (AP-HP), 75013 Paris, France

gilles.montalescot@aphp.fr

See Online for appendix

\section{Research in context}

\section{Evidence before this study}

The $\mathrm{P}_{2} \mathrm{Y}_{12}$ inhibitors prasugrel and ticagrelor provide a higher level of platelet inhibition than clopidogrel, with a faster onset of action and improved clinical outcomes in patients with acute coronary syndrome. These two drugs have not been well investigated in elective percutaneous coronary intervention (PCI) for stable coronary patients and clopidogrel remains the standard of care. Nevertheless, in 2018, European guidelines on revascularisation gave a llb recommendation to prasugrel and ticagrelor in elective $\mathrm{PCl}$ for high-risk situations but without supporting evidence (level of evidence $C$ ), resulting in increasing use of these drugs in clinical practice. Hard clinical events are rare after elective $\mathrm{PCI}$ but peri-procedural myocardial infarction (type 4a) and myocardial injury are frequent, especially in high-risk situations, and have been associated with a poorer prognosis. Whether ticagrelor could reduce periprocedural myonecrosis in high-risk elective $\mathrm{PCl}$ is unknown. To our knowledge, no oral $\mathrm{P}_{2} \mathrm{Y}_{12}$ inhibitor other than clopidogrel has been appropriately tested in combination with aspirin in elective $\mathrm{PCl}$ before this study was undertaken.

\section{Added value of this study}

We showed that the higher level of platelet inhibition obtained with ticagrelor compared with clopidogrel did not translate into

assessment of loading with the $\mathrm{P}_{2} \mathrm{Y}_{12}$ inhibitor ticagrelor or clopidogrel to halt ischaemic events in patients undergoing elective coronary stenting (ALPHEUS) study examined the effect of ticagrelor compared with clopidogrel to reduce periprocedural myocardial necrosis in stable coronary patients undergoing high-risk elective PCI.

\section{Methods}

\section{Study design and participants}

The ALPHEUS study, a phase 3b, randomised, open-label trial, was done at 49 hospitals in France and Czech Republic. The participating centres, investigators, and study committee members are listed in the appendix (pp 3-13). The study design and protocol have been previously published ${ }^{10}$ and approved by the national regulatory authorities and ethics committees or institutional review boards as needed in the participating countries.

Patients with stable coronary artery disease, defined as having a baseline cardiac troponin below the upper limit of the normal or a decreasing level in case of modestly positive cardiac troponin (within the grey zone specific to each high sensitivty troponin assay or below three times the upper limit of the local laboratory normal values), were eligible for the study if they had an indication for PCI and at least one high-risk characteristic (list provided in appendix p 16). Exclusion criteria have been described previously. ${ }^{10}$ Patients who were on chronic clopidogrel treatment (maintenance dose for more than 5 days) were a reduction of periprocedural myocardial infarction or myocardial injury within $48 \mathrm{~h}$ of high-risk $\mathrm{PCl}$ in stable coronary patients. None of the clinical outcomes differed between groups at 30-day follow-up, whereas there was an excess of minor bleeding but not of major bleeding in patients treated with ticagrelor.

\section{Implications of all the available evidence}

During the conduct of the ALPHEUS study, prasugrel was also compared with clopidogrel in another elective PCI study (the SASSICAIA study). However, this study was ended prematurely after inclusion of 781 patients because of slow enrolment and insufficient funding. We did a pooled analysis of the global data available, representing 2664 stable coronary patients undergoing elective $\mathrm{PCl}$ with clopidogrel or stronger $P 2 Y_{12}$ inhibition using ticagrelor or prasugrel. None of the studies reported an excess of major bleeding with more potent P2Y $Y_{12}$ inhibitors, but the results were consistent in showing an absence of improved efficacy. Overall, our findings suggest that clopidogrel should remain the recommended standard of care in stable coronary patients undergoing $\mathrm{PCl}$.

eligible for the study. All patients provided written informed consent.

\section{Randomisation and masking}

Eligible patients were randomly assigned (1:1) to either ticagrelor or clopidogrel by use of an interactive web response system available via the electronic case report form, and stratified by centre. The study was open label, as a full double-blind design was not possible because of budget constraints across the two European countries. However, the primary endpoint was based on the measurement of post-PCI troponin, which is not subject to interpretation or bias, and the clinical endpoints were all adjudicated in a masked fashion, in addition to reading of PCI videos at a central core laboratory and statistical analyses. Administration of the loading dose of the study drug took place after the angiogram and before PCI, which could be staged (deferred PCI within $24 \mathrm{~h}$ of administration of the loading dose of study drug) or immediately after randomisation (ad-hoc PCI was defined as within $3 \mathrm{~h}$ after the angiogram). Random assignment could not occur before the coronary status was known.

\section{Procedures}

Patients received a loading dose of ticagrelor $180 \mathrm{mg}$ before PCI and $90 \mathrm{mg}$ twice daily thereafter for 30 days or a loading dose of clopidogrel 300-600 mg (dose at the discretion of the physician) and $75 \mathrm{mg}$ daily thereafter for 
30 days. Investigators could administer the loading dose as whole or crushed tablets. The duration of study treatment was 30 days after PCI. Beyond 30 days, the choice of treatment was left at the discretion of the treating physician. A pharmacodynamic substudy (the Bio-ALPHEUS study) was done at five participating centres and analysed the level of $\mathrm{P} 2 \mathrm{Y}_{12}$ inhibition in a masked fashion at the ACTION central core laboratory (Paris, France). Samples were drawn at baseline, $4 \mathrm{~h}$ after the loading dose, and the day after PCI and platelet inhibition was evaluated using the vasodilator-stimulated phosphoprotein platelet reactivity index measured by ELISA, as previously described. ${ }^{11}$

\section{Outcomes}

The primary outcome was PCI-related myocardial infarction (type $4 \mathrm{a}$ or $4 \mathrm{~b}$ ) or major myocardial injury within $48 \mathrm{~h}$ of the procedure (or at hospital discharge if earlier). The definitions $^{10}$ have been previously published and are reported in the appendix ( $p$ 15). The definition of the primary outcome of the ALPHEUS trial corresponded to the third universal definition of myocardial infarction that was effective at the time of the study design. ${ }^{12}$ The fourth universal definition of myocardial infarction was published while the study was ongoing, and the protocol was amended to include the new definition of myocardial injury in the main secondary outcome, combining PCIrelated myocardial infarction (type $4 \mathrm{a}$ or $4 \mathrm{~b}$ ) and any type of myocardial injury (major or minor). ${ }^{13}$

Other secondary outcomes included the composite of death, myocardial infarction (all type), or stroke or transient ischaemic attack; the composite of death or myocardial infarction (type 1,4, and 5); and the composite of death, myocardial infarction (type 1, 4, and 5), major myocardial injury, urgent revascularisation, or recurrent ischaemia requiring catheterisation.

The primary safety outcome was major bleeding, evaluated by the Bleeding Academic Research Consortium (BARC) criteria (BARC 3 or 5). Secondary safety outcomes

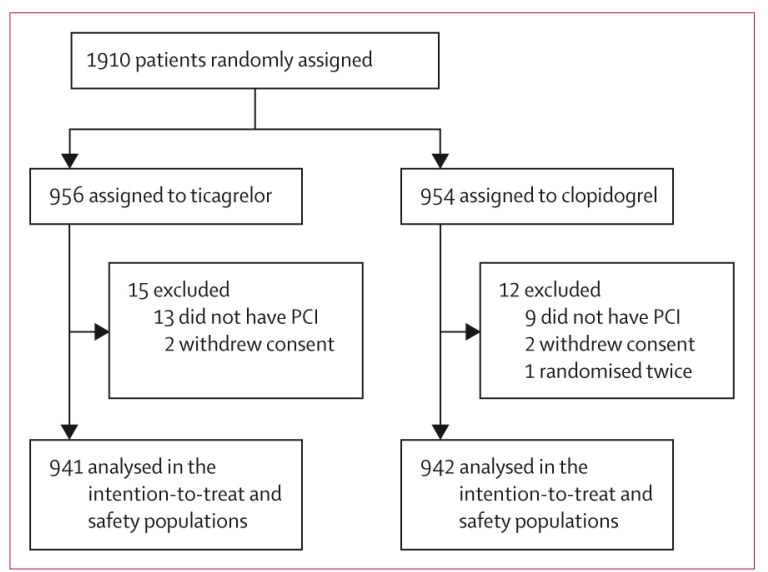

Figure 1: Trial profile

$\mathrm{PCl}=$ percutaneous coronary intervention. included minor or nuisance bleeding (BARC 1 or 2) and any bleeding (BARC 1 to 5). A net clinical benefit outcome comprising death, myocardial infarction, stroke, or major bleeding was also evaluated.

Bleeding risk was evaluated with the Dual Antiplatelet Therapy (DAPT) score and the PARIS bleeding score. . $^{14.15}$ In addition to the baseline level, cardiac troponin was measured $6 \mathrm{~h}$ and $24 \mathrm{~h}$ after PCI or at discharge if this occurred earlier, and the peak values were considered for outcome assessment. Clinical outcomes were evaluated at $48 \mathrm{~h}$ and 30 days. All angiographic or PCI videos were analysed by at least two masked independent experts (who did not otherwise participate in the study) of the ACTION central core laboratory. An independent clinical event committee whose members were unaware of the treatment assignments reviewed all outcomes, except death.

\begin{tabular}{|c|c|c|}
\hline & $\begin{array}{l}\text { Ticagrelor } \\
(n=941)\end{array}$ & $\begin{array}{l}\text { Clopidogrel } \\
(n=942)\end{array}$ \\
\hline Age, years & $66 \cdot 0(9 \cdot 2)$ & $66.6(9 \cdot 7)$ \\
\hline \multicolumn{3}{|l|}{ Sex } \\
\hline Female & $177(19 \%)$ & $207(22 \%)$ \\
\hline Male & $764(81 \%)$ & $735(78 \%)$ \\
\hline Body-mass index, $\mathrm{kg} / \mathrm{m}^{2}$ & $27.8(4 \cdot 5)$ & $27 \cdot 6(4 \cdot 9)$ \\
\hline Current smoker & $166(18 \%)$ & $171(18 \%)$ \\
\hline Hypertension & $594(63 \%)$ & $607(64 \%)$ \\
\hline Diabetes & $328(35 \%)$ & $352(37 \%)$ \\
\hline Dyslipidaemia & $581(62 \%)$ & $570(61 \%)$ \\
\hline $\begin{array}{l}\text { Renal insufficiency (creatinine } \\
\text { clearance }<60 \mathrm{~mL} / \mathrm{min} \text { ) }\end{array}$ & $89(9 \%)$ & $98(10 \%)$ \\
\hline \multicolumn{3}{|l|}{ Medical history* } \\
\hline $\begin{array}{l}\text { History of acute coronary syndrome } \\
\text { (in the past } 12 \text { months) }\end{array}$ & $51(5 \%)$ & $50(5 \%)$ \\
\hline $\begin{array}{l}\text { Previous coronary artery bypass } \\
\text { grafting }\end{array}$ & $62(7 \%)$ & $60(6 \%)$ \\
\hline Previous PCl & $339(36 \%)$ & $362(38 \%)$ \\
\hline Peripheral vascular disease & $121(13 \%)$ & $115(12 \%)$ \\
\hline $\begin{array}{l}\text { Previous stroke or transient } \\
\text { ischaemic attack }\end{array}$ & $43(5 \%)$ & $49(5 \%)$ \\
\hline $\begin{array}{l}\text { Left ventricular ejection fraction }<40 \% \\
\text { or previous episode of heart failure }\end{array}$ & $46(5 \%)$ & $49(5 \%)$ \\
\hline \multicolumn{3}{|l|}{ Treatment on admission } \\
\hline Proton pump inhibitors $\dagger$ & $338(36 \%)$ & $347(37 \%)$ \\
\hline Aspirin & $814(87 \%)$ & $804(85 \%)$ \\
\hline Clopidogrel* & $388(41 \%)$ & $417(44 \%)$ \\
\hline \multicolumn{3}{|l|}{ Procedural characteristics } \\
\hline Number of high-risk features for $\mathrm{PCl}$ & $3 \cdot 2(1 \cdot 4)$ & $3 \cdot 2(1 \cdot 5)$ \\
\hline Radial or ulnar approach $\dagger$ & $891(95 \%)$ & 895 (95\%) \\
\hline Multivessel disease & $575(61 \%)$ & $586(62 \%)$ \\
\hline $\begin{array}{l}\text { Number of stents implanted per } \\
\text { patient }\end{array}$ & $1.8(1.0)$ & $1.8(1 \cdot 0)$ \\
\hline Total stent length per patient, mm & $38 \cdot 4(24 \cdot 5)$ & $38 \cdot 9(24 \cdot 8)$ \\
\hline \multicolumn{3}{|c|}{$\begin{array}{l}\text { Data are mean }(\mathrm{SD}) \text { or } \mathrm{n}(\%) . \mathrm{PCl}=\text { percutaneous coronary intervention. }{ }^{*} \text { Data } \\
\text { missing for one patient in the ticagrelor group. } † \text { Data missing for two patients in } \\
\text { the ticagrelor group. }\end{array}$} \\
\hline
\end{tabular}




\begin{abstract}
Statistical analysis
Assuming a total event rate (for the primary outcome) of $30 \%$ at $48 \mathrm{~h}$ in the clopidogrel group, we calculated that 856 patients per group (1712 total patients) were required for $80 \%$ power to detect a difference of six percentage points (20\% relative difference) in the primary outcome at a two-sided $\alpha$ level of $5 \%$. Assuming a dropout rate of around 10\%, 950 patients per group (1900 total patients) needed to be randomly assigned. A masked sample size reassessment was done on the primary outcome after $50 \%$ of patients were included for sample size reassessment (Addplan Software release 4) and we concluded that no sample size adjustment was necessary. The primary analysis was based on all events that occurred in the intention-to-treat population, defined as all patients who underwent randomisation and PCI and who provided written informed consent. In cases of withdrawal of consent, only data recorded before the withdrawal were considered. The safety analysis included all patients who received at least one dose of study drug. The primary outcome was analysed by $\chi^{2}$ test. Prespecified subgroup analyses to evaluate variations in treatment effect were done by logistic regression models, with terms for treatment, subgroup, and interaction of
\end{abstract}

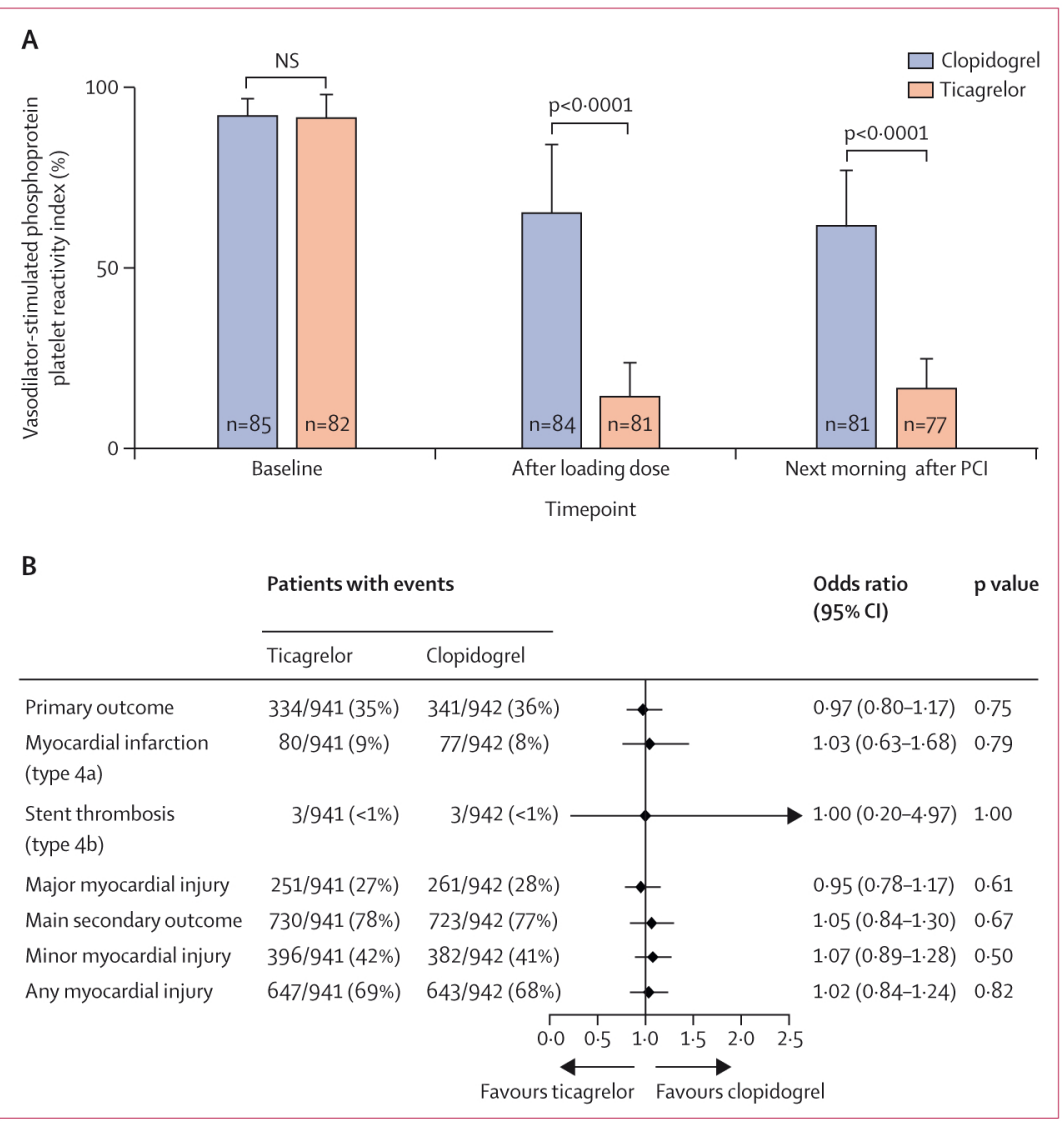

Figure 2: $\mathrm{P}_{2} \mathrm{Y}_{12}$-mediated platelet reactivity measured by the vasodilator-stimulated phosphoprotein in the ticagrelor group and clopidogrel group (A) and primary and secondary outcomes at $48 \mathrm{~h}$ (B)

$\mathrm{NS}=$ not significant. $\mathrm{PCl}=$ percutaneous coronary intervention. treatment with subgroup. All reported subgroup analyses were prespecified. Sensitivity analyses were done for primary and secondary endpoints using multivariate mixed logistic models, including centre as a random effect and with or without a priori known risk factors as covariables (diabetes, renal insufficiency, left ventricular ejection fraction $<40 \%$ or previous episode of heart failure, multivessel disease, number of stents implanted, and total stent length per patient). Secondary outcomes were examined with analyses identical to those described for the primary outcome. Kaplan-Meier estimates of clinical outcomes were also calculated for 30 days after the first dose.

Data were collected and analysed according to the predefined statistical analysis plan by academic statisticians of the ACTION Study Group. A steering committee oversaw the conduct of the trial, in collaboration with representatives of the study sponsor. The trial was monitored by an independent data and safety monitoring board.

All statistical analyses were done using SAS version 9.4 software. The trial was registered with ClinicalTrials.gov, NCT02617290.

\section{Role of the funding source}

The funder of the study had no role in study design, data collection, data analysis, data interpretation, or writing of the report. The corresponding author had full access to all the data in the study and had final responsibility for the decision to submit for publication. All authors had full access to all the data in the study and had final responsibility for the decision to submit for publication.

\section{Results}

Between Jan 9, 2017, and May 28, 2020, 1910 patients were randomly assigned at 49 sites, 956 to the ticagrelor group and 954 to the clopidogrel group (figure 1). 15 patients were excluded from the ticagrelor group and 12 from the clopidogrel group. Trial enrolment ended because the number of planned subjects was reached. Patient baseline characteristics were similar between the study groups, and representative of a population of patients with stable coronary disease (table 1). On admission, the electrocardiogram was normal in 1310 (70\%) of 1883 patients and baseline cardiac troponin was negative in 1736 (93\%) of 1883 patients. Patients with three or more high-risk features represented 1246 (66\%) of 1883 PCI procedures (appendix p 19). The bleeding risk was similar in both study groups when evaluated with the DAPT score, but slightly different, with more patients with low bleeding risk in the ticagrelor group when evaluated with the PARIS score (appendix p 20). .14,15 $^{10}$

A radial approach was used in 1786 (95\%) of 1883 cases and $3202(>99 \%)$ of 3207 stents implanted were drugeluting stents. The loading dose of clopidogrel of $600 \mathrm{mg}$ or more was chosen in $635(67 \%)$ of 942 patients and crushed pills were used more frequently in the ticagrelor 
group than in the clopidogrel group (178 [19\%] of 941 vs 62 [6.7\%] of $942 ; \mathrm{p}<0.0001)$. PCI was done in an ad-hoc setting in 998 (53\%) of 1883 patients, with no difference between the ticagrelor and clopidogrel groups $(p=0.47)$, and deferred PCI was done in a median of 1.9 days (IQR 0.9-7.0), with no difference between the ticagrelor and clopidogrel groups $(\mathrm{p}=0 \cdot 27)$. The median delay from random assignment to PCI was $2 \cdot 0 \mathrm{~h}$ (IQR $0 \cdot 3-5 \cdot 0$ ) in the ticagrelor group and $2 \cdot 1 \mathrm{~h}(0 \cdot 3-4 \cdot 8)$ in the clopidogrel group. The median delay from loading dose to PCI was $1.7 \mathrm{~h}(0 \cdot 3-4 \cdot 1)$ in the ticagrelor group and $1.8 \mathrm{~h}(0 \cdot 3-4 \cdot 2)$ in the clopidogrel group.

The main results of the masked prespecified platelet substudy in 167 patients showed that P2Y $\mathrm{Y}_{12}$-mediated platelet reactivity was significantly lower with ticagrelor than with clopidogrel when measured a mean of $4 \cdot 1 \mathrm{~h}$ (SD 1.0) after the loading dose and the next day after PCI, a mean of $21.6 \mathrm{~h}(2.5)$ after the loading dose (figure $2 \mathrm{~A}$ ).

At $48 \mathrm{~h}$, the primary composite efficacy outcome of periprocedural myocardial infarction and major myocardial injury was observed in 334 (35\%) of 941 patients in the ticagrelor group and 341 (36\%) of 942 patients in the clopidogrel group (odds ratio $0.97,95 \% \mathrm{CI}$ $0 \cdot 80-1 \cdot 17 ; \mathrm{p}=0 \cdot 75$; figure $2 \mathrm{~B})$. Results were consistent across the individual components of the primary outcome (figure 2B) and across most prespecified subgroups for the primary outcome (appendix p 18). We also adjusted these results on established risk factors for periprocedural events (diabetes, renal insufficiency, left ventricular ejection fraction $<40 \%$ or previous episode of heart failure, multivessel disease, the number of stents implanted, and the total stent length per patient) and the findings were unchanged (data not shown). The main secondary outcome, comprising periprocedural myocardial infarction and any form of myocardial injury, was similar between the two groups (figure 2B). We observed no significant difference between the study groups for all secondary efficacy outcomes at 30-day follow-up (table 2; figure 3A). Results for the primary and main secondary outcome were similar in sensitivity analyses using mixed logistic regression models $(\mathrm{p}=0.77$ and $\mathrm{p}=0.81$, for the primary outcome and main secondary outcome, respectively). The rates of major complications were low for the hard clinical endpoint with nine stent thromboses, three strokes or transient ischaemic attacks, two deaths, and seven major bleeding episodes at 30 days, over the entire population of 1883 patients.

The primary safety outcome (major bleeding) occurred in only one patient at $48 \mathrm{~h}$ and was infrequent and similar in both groups at 30 days (table 3 ). The rate of minor bleeding was not different at $48 \mathrm{~h}$ but was more frequent in the ticagrelor group compared with the clopidogrel group at 30 days, as was the rate of any bleeding (table 3; figure 3B). The net clinical benefit outcome did not differ between the study groups (table 2). Non-bleeding adverse events, especially dyspnoea, were more frequent in the

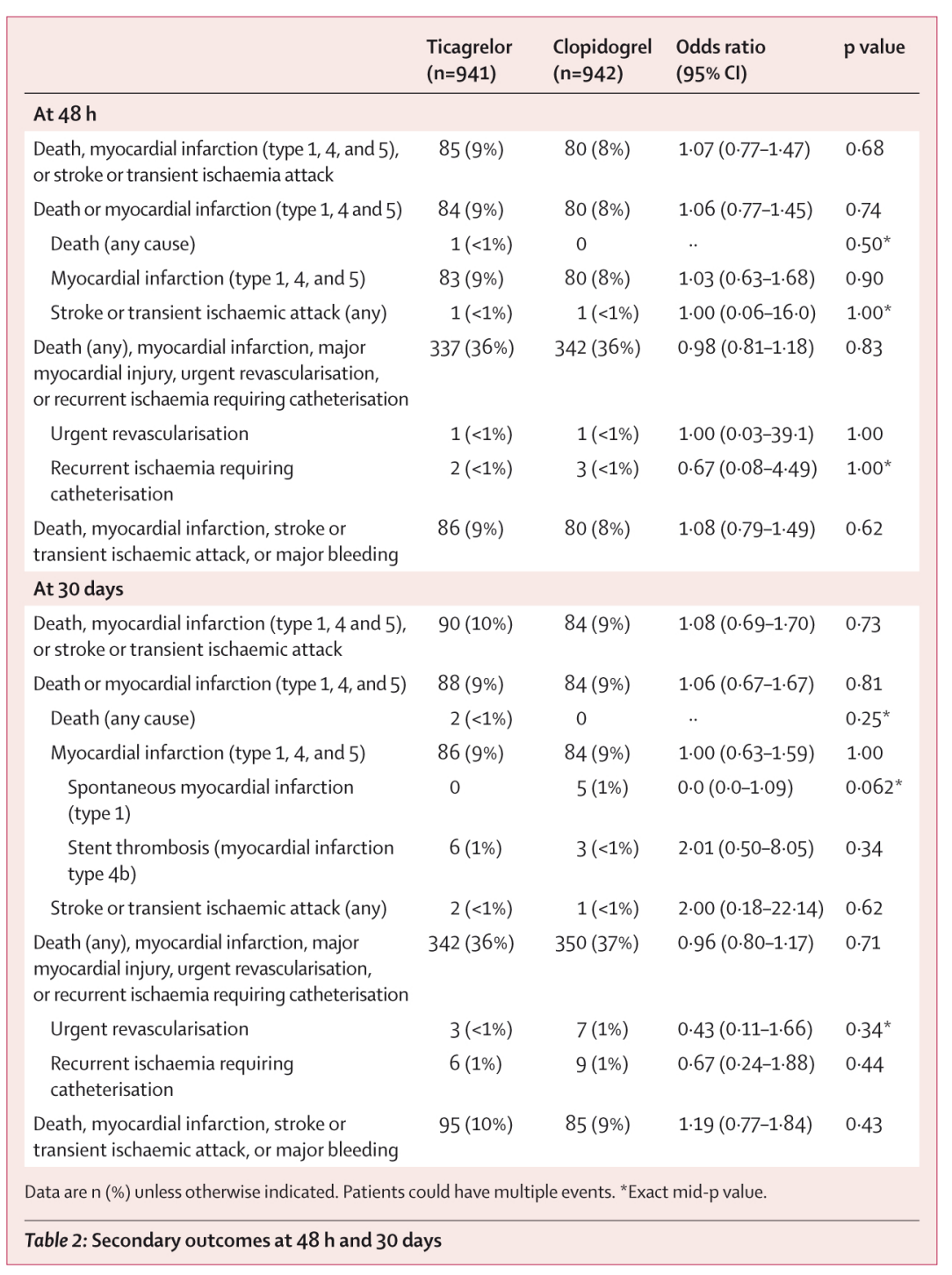

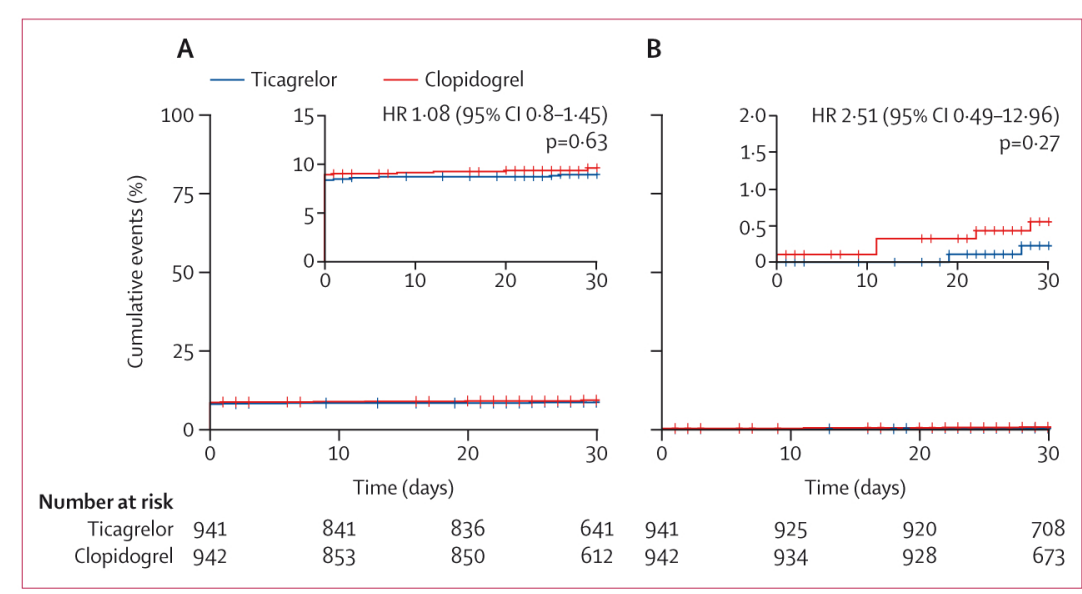

Figure 3: Kaplan-Meier curves for death, myocardial infarction, or stroke or transient ischaemic attack (A) and major bleeding (Bleeding Academic Research Consortium 3 to $5 ; \mathrm{B}$ ) at 30 days for ticagrelor versus and clopidogrel

$\mathrm{HR}=$ hazard ratio. 
ticagrelor group (105 [11\%] of 956 patients) compared with the clopidogrel group (five $[<1 \%]$ of 954 patients) and led to more frequent discontinuation of study drug (21 [2\%] of 956 patients in the ticagrelor group vs four $[<1 \%]$ of 954 patients in the clopidogrel group).

\section{Discussion}

Despite a higher level of platelet inhibition, ticagrelor was not superior to clopidogrel in reducing periprocedural myocardial infarction or myocardial injury within $48 \mathrm{~h}$ of high-risk PCI in stable coronary patients. Moreover, none of our clinical outcomes differed between the study groups at 30-day follow-up. The more potent platelet inhibitory effect of ticagrelor translated to increased minor bleeding.

Our study supports the safety of elective percutaneous revascularisation, with low rates of complications. By contrast, periprocedural myonecrosis was frequent in this study, with a similar level to other studies during the past decade that have used sensitive definitions of myocadial injury and infarction and troponin as a biomarker, but could be more related to mechanical rather than thrombotic causes. ${ }^{16}$ Our primary outcome included myocardial infarction type 4a (157 [8\%] events), type $4 \mathrm{~b}$ (six $[<1 \%]$ events), and myocardial injury as defined in the third universal definitions of myocardial infarction, which were available when the study was

\begin{tabular}{|c|c|c|c|c|}
\hline & $\begin{array}{l}\text { Ticagrelor } \\
(n=941)\end{array}$ & $\begin{array}{l}\text { Clopidogrel } \\
(n=942)\end{array}$ & $\begin{array}{l}\text { Odds ratio } \\
(95 \% \mathrm{Cl})\end{array}$ & $\mathrm{p}$ value \\
\hline \multicolumn{5}{|l|}{ At $48 \mathrm{~h}$} \\
\hline Major bleeding events (BARC 3 or 5 ) & $1(<1 \%)$ & 0 & .. & $0.50^{*}$ \\
\hline Nuisance or minor bleeding (BARC 1 or 2) & $63(7 \%)$ & $50(5 \%)$ & $1.28(0 \cdot 87-1.88)$ & 0.20 \\
\hline Any bleeding (BARC 1 to 5 ) & $64(7 \%)$ & $50(5 \%)$ & $1 \cdot 30(0 \cdot 89-1 \cdot 91)$ & 0.17 \\
\hline \multicolumn{5}{|l|}{ At 30 days } \\
\hline Major bleeding events (BARC 3 or 5 ) & $5(1 \%)$ & $2(<1 \%)$ & $2 \cdot 51(0.49-13 \cdot 0)$ & $0.29^{*}$ \\
\hline Nuisance or minor bleeding (BARC 1 or 2 ) & $105(11 \%)$ & $71(8 \%)$ & $1 \cdot 54(1 \cdot 12-2 \cdot 11)$ & 0.0070 \\
\hline Any bleeding (BARC 1 to 5 ) & $110(12 \%)$ & $73(8 \%)$ & $1.58(1.15-2.15)$ & 0.0039 \\
\hline \multicolumn{5}{|c|}{ Data are $\mathrm{n}(\%)$ unless otherwise indicated. BARC=Bleeding Academic Research Consortium. *Exact mid-p value. } \\
\hline
\end{tabular}

designed (512 [27\%] events). ${ }^{11}$ Our main secondary outcome, which included all degrees of myocardial injury, is aligned with the recent fourth universal definition of myocardial infarction, ${ }^{12}$ which appears to be very sensitive, as 1453 (77\%) of 1883 patients in our study had some degree of myocardial injury or infarction. Irrespective of the definition and severity of post-procedural myonecrosis, we found no difference between the two study treatments. There is continuing debate over the best definition and clinical impact of these biologically driven events after revascularisation, and PCI in particular. However, several studies and metanalyses have reported that periprocedural myonecrosis, even of limited magnitude, is associated with adverse cardiac events and all-cause mortality. ${ }^{1-4,17}$

Failure of ticagrelor to prevent myonecrosis caused by PCI in stable patients with high-risk features contrasts with the effect of this drug in patients with acute coronary syndrome, ${ }^{18}$ which is a different situation with a more thrombotic physiopathology at the time of PCI. In the present study, drug treatment was initiated before PCI in all patients and the results were consistent whatever the delay in administration before PCI. Our results are aligned with other studies in elective PCI, ${ }^{19-21}$ and we provide results of a pooled analysis of available global randomised data (ALPHEUS and SASSICAIA trials), representing 2664 stable coronary patients undergoing elective PCI and showing no benefit of stronger P2 $\mathrm{Y}_{12}$ inhibition using ticagrelor or prasugrel compared with clopidogrel to decrease periprocedural complications (figure 4). Our results are also aligned with studies of PCI in patients with non-ST elevation acute coronary syndrome, ${ }^{22-24}$ showing that oral antiplatelet pretreatment might cause more harm than benefit in patients treated with PCI. Our pharmacodynamic data show that ticagrelor was more potent than clopidogrel $4 \mathrm{~h}$ after the loading dose, with more than half of patients having high levels of $\mathrm{P}_{2} \mathrm{Y}_{12}$-mediated platelet reactivity in the clopidogrel group, as well as the next day after PCI, in line with previous pharmacodynamic studies in elective PCI. ${ }^{25,26}$ The disconnect between pharmacodynamics and

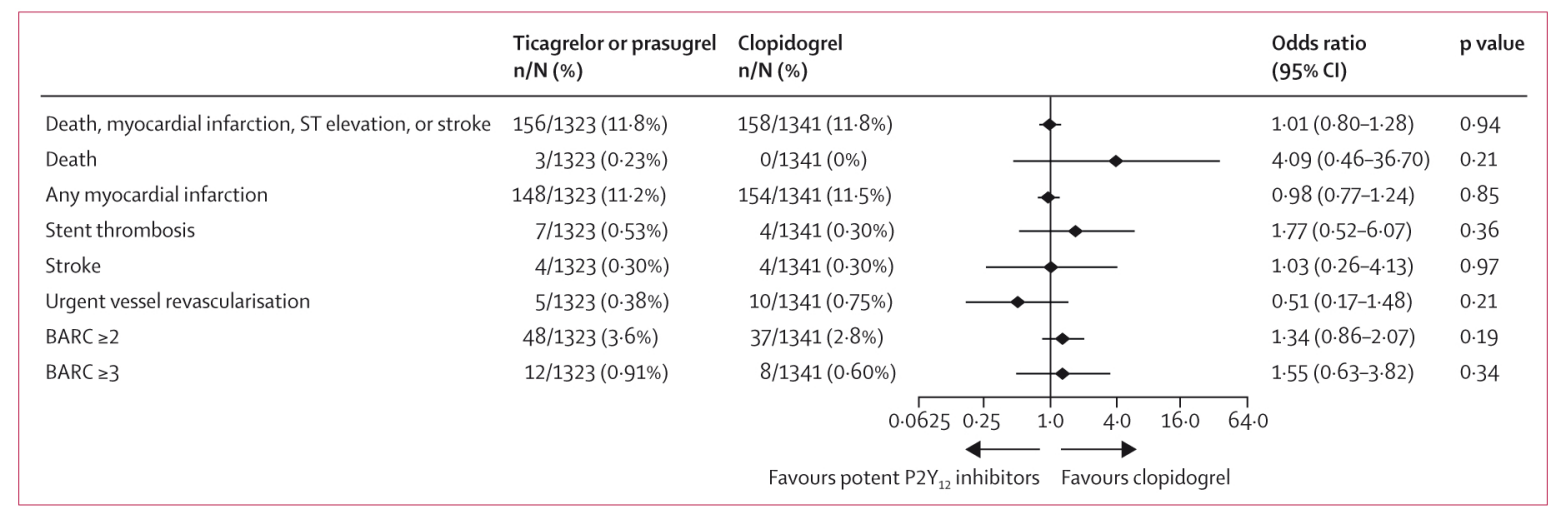


clinical outcomes in the ALPHEUS trial has also been observed in other clinical situations. ${ }^{27}$ Whether stronger and more rapid platelet inhibition is needed to reduce periprocedural myonecrosis is a relevant question. Previous trials have shown a reduction in cardiac marker release and periprocedural events when using intravenous drugs such as glycoprotein IIb/IIIa inhibitors or cangrelor. ${ }^{28-30}$ These drugs immediately provide a more potent effect than that obtained with oral $\mathrm{P}_{2} \mathrm{Y}_{12}$ inhibitors.

Regarding safety and adverse events, procedures were done almost exclusively with radial access, therefore limiting the risk of access site major bleeding, with little non-access site bleeding (eg, ecchymosis or epistaxis) showing the safety of 30-day dual antiplatelet therapy with both drugs. Beyond 30 days, de-escalation studies have suggested improved safety with single antiplatelet therapy (vs dual antiplatelet therapy) in elective PCI. ${ }^{31}$

This trial has limitations related to its design. First, this was an open-label trial with inherent biases that were controlled by the use of the prospective, randomised, open-label, blinded endpoint design, which comprised masked adjudication of all outcomes, masked measurement of troponin after PCI, and an independent masked review of all PCI videos by core laboratory expert readers. Second, the trial does not provide reliable information on hard clinical outcomes, which are rare in elective PCI. Third, all types of troponin assays were authorised in this trial to reflect real-life PCI centres but might have brought heterogeneity, as prognosis thresholds might be dependent on the type of assay used. Fourth, our study included patients on chronic clopidogrel therapy, which represented almost half the study population and could potentially have blunted the differential effect compared with ticagrelor. However, our prespecified subgroup analysis of clopidogrel-naive patients does not support this hypothesis. Finally, whether a similar strategy would have resulted in a different outcome in a population of patients with poor response to clopidogrel with high platelet reactivity is unknown.

In conclusion, in patients undergoing elective highrisk PCI, treatment with ticagrelor showed no difference compared with clopidogrel in reduction of periprocedural myocardial necrosis. Treatment with ticagrelor did not cause an increase in major bleeding but increased the rate of minor bleeding at 30 days. The results of the ALPHEUS trial support the use of clopidogrel as the standard of care for elective PCI in addition to aspirin and pave the way for the evaluation of other strategies to lower periprocedural myonecrosis after elective PCI.

\section{Contributors}

JS and GM designed the study, analysed and interpreted the data, and wrote the first draft of the paper. EV analysed the data. All authors were involved with data interpretation, reviewed and revised the draft of the manuscript, and approved the final version for submission. J-PC and GC have verified the underlying data.

\section{Declaration of interests}

IS reports receiving consulting and lecture or travel support from AstraZeneca, Bayer HealthCare SAS, Biotronik, BPI France,
Boehringer Ingelheim France, CSL Behring SA, Gilead Science, Sanofi-Aventis France, Terumo France SAS, Abbott Medical France SAS, and Zoll. JS is a stockholder of Pharmaseeds. BL has received research grants from Biotronik, Boston Scientific, Daiichi-Sankyo, Fédération Française de Cardiologie, and Institute of CardioMetabolism and Nutrition, consultant fees from Daiichi-Sankyo and Eli Lilly, and lecture fees from AstraZeneca, Medtronic, and Novartis. FBe reports receiving consulting and lecture fees from AstraZeneca, Bristol-Myers Squibb, Medtronic, Biosensors, and Boston Scientific, and institutional research grants from Medtronic, Biosensors, Acist, and Boston Scientific. GR reports receiving speaker or consulting fees from Abbott. $\mathrm{ZM}$ reports receiving consulting or speaker fees from AstraZeneca.

J-GD reports receiving consulting and lecture fees from AstraZeneca, Bayer, Boehringer-Ingelheim, Bristol-Myers Squibb/Pfizer, and Sanofi, and grants from Bayer, Bristol-Myers Squibb/Pfizer, and Biosensors. ZB reports institutional research grants from Medtronic and Microport, and lecture or travel support from Abbott Vascular, Microport, Boston Scientific, and Biotronik. TL reports consulting or speaker fees from AstraZeneca, Boston Scientific, and Abbott, and a research grant from AstraZeneca. CP reports consulting or speaker fees from Abbott Vascular. FBo reports consulting or speaker fees from Amgen, Gilead, ViiV Healthcare, Amgen, Sanofi, MSD, and Servier, outside the submitted work. ML reports fellowship grants from Medtronic, Biotronik, and Boston Scientific. GD reports consulting or speaker fees Amgen, AstraZeneca, Bayer, Bristol-Myers Squibb, Janssen, Sanofi, and Terumo, consulting fees from Boston Scientific and Novo Nordisk, and travel fees from, AstraZeneca, Bayer, and Bristol-Myers Squibb. $\mathrm{J}-\mathrm{PC}$ reports receiving consulting and lecture fees from AstraZeneca, Bayer, Bristol-Myers Squibb, Fédération Française de Cardiologie, Lead-Up, and WebMD. GC reports receiving research grants, consultant fees, or lectures fees from Amgen, AstraZeneca, Abbott, Bayer, Biotronik, Bristol-Myers Squibb, Pfizer, and Sanofi-Aventis. $\mathrm{KB}$ reports speaker or congress fees from Abbott, Medtronic, Novartis, and Teleflex. PK reports consulting or speaker fees from Boston Scientific, Medtronic, Bayer, AstraZeneca, Pfizer, Edwards Sciences, and Boehringer Ingelheim, and research support from Novartis, Zoll, and Amgen. EV reports consulting or speaker fees from Abbott, Bristol-Myers Squibb, Celgene, Edwards, Pfizer, Sanofi, and Novartis. GM reports consulting or speaker fees from Abbott, AIM Group, Amgen, Actelion, American College of Cardiology Foundation, AstraZeneca, Axis-Santé, Bayer, Boston Scientific, Bristol-Myers Squibb, Beth Israel Deaconess Medical, Brigham Women's Hospital, Fréquence Médicale, ICOM, Idorsia, Elsevier, Fédération Française de Cardiologie, Fréquence Médicale, ICAN, Lead-Up, Menarini, Medtronic, MSD, Novo Nordisk, Pfizer, Quantum Genomics, Sanofi Aventis, SCOR Global Life, Servier, and WebMD. All other authors report no competing interests.

\section{Data sharing}

Data collected for the study, including individual participant data and a data dictionary defining each field in the set, can be made available to others under the following restrictions: with investigator support, after approval of a proposal by the Allies in Cardiovascular Trials Initiatives and Organized Networks (ACTION) study group and the sponsor of the study, with a signed data access agreement, and with specific funding to access the database. Requests should be sent to johanne.silvain@aphp.fr.

\section{Acknowledgments}

We thank the patients, clinical research assistants, study coordinators, investigators of the ALPHEUS trial, and Karine Brochard, Martine Tanke, and Damien Vanhoye who contributed to the ALPHEUS study. This trial was led by the ACTION Study Group, an academic research organisation based at Pitié-Salpêtrière Hospital (Paris, France), was sponsored by Assistance Publique-Hopitaux de Paris, and was funded by an unrestricted grant from AstraZeneca.

References

1 Prasad A, Rihal CS, Lennon RJ, Singh M, Jaffe AS, Holmes DR Jr. Significance of periprocedural myonecrosis on outcomes after percutaneous coronary intervention: an analysis of preintervention and postintervention troponin T levels in 5487 patients. Circ Cardiovasc Interv 2008; 1: 10-19.
For more on the ACTION Study Group see wwww.action-coeur.org 
2 Feldman DN, Kim L, Rene AG, Minutello RM, Bergman G, Wong SC. Prognostic value of cardiac troponin-I or troponin-T elevation following nonemergent percutaneous coronary intervention: a meta-analysis. Catheter Cardiovasc Interv 2011. 77: $1020-30$.

3 Zeitouni M, Silvain J, Guedeney P, et al. Periprocedural myocardial infarction and injury in elective coronary stenting. Eur Heart J 2018; 39: 1100-09.

4 Li Y, Pei H, Bulluck H, Zhou C, Hausenloy DJ. Periprocedural elevated myocardial biomarkers and clinical outcomes following elective percutaneous coronary intervention: a comprehensive dose-response meta-analysis of 44,972 patients from 24 prospective studies. EuroIntervention 2020; 15: 1444-50.

5 Bhatt DL, Lincoff AM, Gibson CM, et al. Intravenous platelet blockade with cangrelor during PCI. N Engl J Med 2009; 361: 2330-41.

6 Harrington RA, Stone GW, McNulty S, et al. Platelet inhibition with cangrelor in patients undergoing PCI. N Engl J Med 2009; 361: 2318-29.

7 Steg PG, Bhatt DL, Hamm CW, et al. Effect of cangrelor on periprocedural outcomes in percutaneous coronary interventions: a pooled analysis of patient-level data. Lancet 2013; 382: 1981-92.

8 Wiviott SD, Trenk D, Frelinger AL, et al. Prasugrel compared with high loading- and maintenance-dose clopidogrel in patients with planned percutaneous coronary intervention: the prasugrel in comparison to clopidogrel for inhibition of platelet activation and aggregation-thrombolysis in myocardial infarction 44 trial Circulation 2007; 116: 2923-32.

9 Gurbel PA, Bliden KP, Butler K, et al. Randomized double-blind assessment of the ONSET and OFFSET of the antiplatelet effects of ticagrelor versus clopidogrel in patients with stable coronary artery disease: the ONSET/OFFSET study. Circulation 2009; 120: 2577-85.

10 Silvain J, Cayla G, Beygui F, et al. Blunting periprocedural myocardial necrosis: Rationale and design of the randomized ALPHEUS study. Am Heart J 2020; 225: 27-37.

11 Silvain J, Storey RF, Cayla G, et al. P2Y12 receptor inhibition and effect of morphine in patients undergoing primary PCI for ST-segment elevation myocardial infarction. The PRIVATEATLANTIC study. Thromb Haemost 2016; 116: 369-78.

12 Thygesen K, Alpert JS, Jaffe AS, et al. Third universal definition of myocardial infarction. J Am Coll Cardiol 2012; 60: 1581-98.

13 Thygesen K, Alpert JS, Jaffe AS, et al. Fourth universal definition of myocardial infarction (2018). Circulation 2018; 138: e618-51.

14 Baber U, Mehran R, Giustino G, et al. Coronary thrombosis and major bleeding after PCI with drug-eluting stents: risk scores from PARIS. J Am Coll Cardiol 2016; 67: 2224-34.

15 Yeh RW, Secemsky EA, Kereiakes DJ, et al. Development and validation of a prediction rule for benefit and harm of dual antiplatelet therapy beyond 1 year after percutaneous coronary intervention. JAMA 2016; 315: 1735-49.

16 Park DW, Kim YH, Yun SC, et al. Impact of the angiographic mechanisms underlying periprocedural myocardial infarction after drug-eluting stent implantation. Am J Cardiol 2014; 113: 1105-10.

17 Silvain J, Zeitouni M, Paradies V, et al. Cardiac procedural myocardial injury, infarction and mortality in patients undergoing elective PCI: a pooled analysis of patient-level data. Eur Heart $J$ (in press).
18 Wallentin L, Becker RC, Budaj A, et al. Ticagrelor versus clopidogrel in patients with acute coronary syndromes. N Engl J Med 2009; 361: $1045-57$.

19 Steinhubl SR, Berger PB, Mann JT 3rd, et al. Early and sustained dual oral antiplatelet therapy following percutaneous coronary intervention: a randomized controlled trial. JAMA 2002; 288: 2411-20.

20 Widimsky P, Motovská Z, Simek S, et al. Clopidogrel pre-treatment in stable angina: for all patients $>6 \mathrm{~h}$ before elective coronary angiography or only for angiographically selected patients a few minutes before PCI? A randomized multicentre trial PRAGUE-8. Eur Heart J 2008; 29: 1495-503.

21 Mehilli J, Baquet M, Hochholzer W, et al. Randomized comparison of intensified and standard P2Y12-receptor-inhibition before elective percutaneous coronary intervention: the SASSICAIA trial. Circ Cardiovasc Interv 2020; 13: e008649.

22 Silvain J, Rakowski T, Lattuca B, et al. Interval from initiation of prasugrel to coronary angiography in patients with non-STsegment elevation myocardial infarction. J Am Coll Cardiol 2019; 73: 906-14.

23 Tarantini G, Mojoli M, Varbella F, et al. Timing of oral P2Y12 inhibitor administration in non-ST elevation acute coronary syndrome. J Am Coll Cardiol 2020; published online Aug 31. https://doi.org/10.1016/j.jacc.2020.08.053

24 Montalescot G, Bolognese L, Dudek D, et al. Pretreatment with prasugrel in non-ST-segment elevation acute coronary syndromes. N Engl J Med 2013; 369: 999-1010.

25 Angiolillo DJ, Franchi F, Waksman R, et al. Effects of ticagrelor versus clopidogrel in troponin-negative patients with low-risk ACS undergoing ad hoc PCI. J Am Coll Cardiol 2016; 67: 603-13.

26 Orme RC, Parker WAE, Thomas MR, et al. Study of two dose regimens of ticagrelor compared with clopidogrel in patients undergoing percutaneous coronary intervention for stable coronary artery disease (STEEL-PCI). Circulation 2018; 138: $1290-300$.

27 Roe MT, Armstrong PW, Fox KA, et al. Prasugrel versus clopidogrel for acute coronary syndromes without revascularization. $N$ Engl J Med 2012; 367: 1297-309.

28 Gurbel PA, Bliden KP, Zaman KA, Yoho JA, Hayes KM, Tantry US. Clopidogrel loading with eptifibatide to arrest the reactivity of platelets: results of the clopidogrel loading with eptifibatide to arrest the reactivity of platelets (CLEAR PLATELETS) study. Circulation 2005; 111: 1153-59.

29 EPILOG Investigators. Platelet glycoprotein IIb/IIIa receptor blockade and low-dose heparin during percutaneous coronary revascularization. N Engl J Med 1997; 336: 1689-96.

30 Bhatt DL, Stone GW, Mahaffey KW, et al. Effect of platelet inhibition with cangrelor during PCI on ischemic events. N Engl J Med 2013; 368: 1303-13.

31 Watanabe H, Domei T, Morimoto T, et al. Effect of 1-month dual antiplatelet therapy followed by clopidogrel vs 12-month dual antiplatelet therapy on cardiovascular and bleeding events in patients receiving PCI: the STOPDAPT-2 randomized clinical trial. JAMA 2019; 321: 2414-27. 